\title{
ESPELHOS DE ESPELHOS... D. DUARTE NA COMPANHIA DE D. AFONSO DE CARTAGENA ENTRE A CULTURA, A MORAL E A POLÍTICA.
}

\author{
Margarida Garcez Ventura* \\ margaridagarcezventura@gmail.com
}

\begin{abstract}
RESUMO: A presença de D. Afonso de Cartagena na corte de Avis acrescenta à longa tradição dos "espelhos de reis" um novo olhar: baseado tanto nos autores clássicos como na Sagrada Escritura e nos doutores da Igreja, induz o jovem infante herdeiro ao estudo, imitação e transmissão de modelos ascéticos e comportamentais. D. Duarte assume essas exigências, não só para si, mas para a sua corte, como matriz para todos os seus súbditos. Numa didáctica de adequação a cada status, as virtudes exigidas aos príncipes são como que redistribuídas, de modo que todos possam contemplar-se nesses espelhos.
\end{abstract}

PALAVRAS-CHAVE: D. Afonso de Cartagena, corte de Avis, espelhos de reis.

Situamo-nos na antecâmara da corte de D. Duarte ${ }^{1}$. A fazer fé nos testemunhos do monarca e daqueles que com ele conviveram, escutaremos conversas honestas e proveitosas para o corpo e para a alma de todos e para bem comum do reino. Aí, por certo, o ouviremos falar de lealdade e interrogar-nos-emos sobre o que diz, para quem o diz e porquê. Afinal passaram quinhentos e tal anos e, no jogo da essência da humanidade versus a sua existência, ganhará a unidade do género humano, (tema que D. Duarte vislumbrou), essa unidade que também vale para diacronia dos objectivos e estratégias de poder político das quais rei e corte são protagonistas.

Está sobejamente constatada e louvada a vantagem que os historiadores do final da Idade Média portuguesa têm de, através da chamada literatura de Avis, ter acesso ao pensamento dos seus autores, nomeadamente ao de D. Duarte. Todavia, não nos apraz designar por literatura esses escritos, que preferimos contar entre os textos sapienciais, ou tal vez somente entre os textos normativos e de reflexão política, ressalvando assim a sua forte componente experiencial e didáctica.

*Doutora em História Medieval pela Universidade de Lisboa. Professora da Faculdade de Letras da Universidade de Lisboa. Membro da Academia Portuguesa da História. 
Há muito que Jacques Le Goff chamou a atenção para a natureza funcional dos intelectuais da Idade Média: eclesiásticos ou leigos estão sempre ao serviço de algum papa, bispo, ou senhor eclesiástico ou leigo, em particular dos reis. A geração de Avis tinha obviamente responsabilidades governativas próprias e há que tirar consequências deste facto quando lemos os seus escritos. Essas responsabilidades de governança desenham considerações só aparentemente teóricas, orientadas por um complexo sistema de situações de vária ordem, quer nacional, quer internacional. Por outro lado, os programas de governo da dinastia avisina possuem, a montante, uma forte carga teórica... bebida directa ou indirectamente em legistas e teólogos, muitos deles presentes na corte.

Servem todas estas considerações para entender quão legitimamente nos podemos movimentar pelos escritos de D. Duarte em particular pelo Leal Conselheiro, e comecemos a centrar o nosso discurso - como peças fundamentadas e operativas na sua relação com o concreto do reino (VENTURA, 2010, pp. 125-141 e 2013 b; CAMPOS SOUTO 2004, n. 67)

D. Duarte escreve o que escreve (e lê o que lê) como actividade inerente ao seu ofício real ${ }^{2}$. Se é verdade que o rei deverá "pautar a sua conduta pela conduta divina, ser a imagem terrena do Senhor" (ALBUQUERQUE, 2012, Cap. V), deverá, como consequência do seu ofício, conduzir o reino na verdade, na justiça e na paz. Porém, não se trata somente conduzir o reino como entidade abstracta, mas deverá também vigiar, louvar e castigar cada um dos súbditos e ser exemplo de todos. Como fundamento desta relação de pai e de pastor (como se dirá mais tarde) está a responsabilidade do rei pela salvação dos súbditos.

A responsabilidade pela salvação dos povos e de cada um dos súbditos, foi, durante toda a medievalidade, mais do que repartida, disputada entre Igreja e realeza. E, à medida que nos aproximamos do final da Idade Média, ou melhor, como um dos sinais de "outra idade" que vai surgindo, o rei assume para si essa responsabilidade da qual afirma que o Senhor lhe pedirá contas (CRISPIM, 1995) ${ }^{3}$.

Já tivemos ocasião de clarificar que D. Duarte considerava que a prossecução da virtude com vista à salvação se situava em formas muito concretas e ligadas ao quotidiano de cada um, de acordo com o seu status (VENTURA, 2011a, p. 243-271) 
Voltaremos a esta ideia, mas por agora bastará insistir na obrigação de ensinar os seus súbditos. A tarefa começa na gente da sua casa ${ }^{4}$ e na corte (VENTURA, 2004, pp. 7996).

D. Duarte herda e constrói essa função educativa da corte $^{5}$, realçando a sua exemplaridade. Reparemos na passagem do Leal Conselheiro ${ }^{6}$, onde o monarca mostra como se forma e se modifica a condição humana. Começa assim: "Da terra, compleição. Do leite e viandas, criação. Dos parentes, nação. Das doenças e acontecimentos, ocasião. Das planetas, constelação. Dos senhores e amigos, conversação. De Nosso Senhor Deus por especial inspiração nos é outorgada condição e discrição." (Cap. XXXIX) Ao desenvolver o contributo da "conversaçom" - a que chamaríamos convivialidade ou sociabilidade - escreve: "por experiência bem se mostra nas cortes dos senhores, reinos e mosteiros como grande parte dos súbditos seguem seu senhor e amigos. Ca bem visto é, graças a Nosso Senhor, como todos os moradores destes reinos em tempos dos mui virtuosos reis, meus senhores Padre e madre [...], avançaram em grandes corações, bom regimento de suas vidas e outras manhas e virtudes mais do que ante eram".

D. Duarte considera, pois, a corte como local de ensino e de aprendizagem global. Foi assim na corte de seus pais e será assim que ele, enquanto príncipe herdeiro associado ao trono e enquanto rei a vai projectar e executar, como se de uma obra de arte se tratasse, muito para além do que Burckhardt poderia imaginar...

Sejam quais forem os instrumentos de análise e metodologia que possamos perfilhar - vindos de Burckhardt, de Johan Huizinga ou de Norberto Elias - a corte afirma-se pelas funções que exerce. Uma dessas funções é ser um local de exemplaridade. Com efeito, entre as operacionalidades da corte - e não certamente a menos significativa em termos da construção do estado moderno - está a exibição de matrizes. Os procedimentos burocráticos, as formas de tratamento, a moda do vestuário, o desenrolar das refeições... assim como os comportamentos éticos e religiosos, tanto como os da coesão social e política, são como que reflectidos e projectados para uma dimensão exterior ${ }^{7}$. Mais: na corte de D. João I, um rei cuja subida ao trono carecia de ser legitimada e justificada, é na corte que se constroem os laços da nova nobreza e das novas clientelas, as quais é necessário reproduzir e implantar por todo o território.

Julgamos pois estar esclarecida a corrente de exemplaridade cujos elos, à semelhança das "benfeitorias", unem o rei à corte e a corte a todos os súbditos. Assim 
sendo, note-se quão fundamental será a excelência da pessoa régia e quão fundamental serão os saberes inculcados nos que hão-de herdar o trono. No caso que agora nos ocupa, pode adivinhar-se quão cuidada deverá ter sido a educação de D. Duarte, pois é ele que, na verdade, consolidará a credibilidade da nova dinastia, dentro e fora do reino.

E certo que a educação dos príncipes é tanto mais urgente quanto, a partir do século XII, a hereditariedade se impõe como regra da sucessão ao trono, ou seja, a sucessão hereditária impõe redobrado cuidado na educação do herdeiro da coroa, funcionando a sua cuidadosa formação como contraponto da aceitação da via hereditária para a transmissão do poder. Mas também, como atrás dissemos, a formação global do infante sucessor de um rei-fundador de uma nova dinastia torna-se imperativo político. $\mathrm{Na}$ época e caso que agora nos ocupa, isto era praticado de tal forma que marcará a obra do célebre D. Afonso de Cartagena durante e após as suas estadas na corte portuguesa ${ }^{8}$.

Não importa aqui traçar a biografia desta personagem crucial, não só da história peninsular, mas da cristandade, nas suas dimensões diplomática, cultural e religiosa. Há uma vintena de anos que investigadores espanhóis, entre os quais devemos destacar Abdón Salazar, Luís Fernández Gallardo, José Maria Viña Liste e Mar Campos Souto (2004, p. 11- 16) têm vindo a destacar a sua singular relação com a corte avisina; quanto à interacção com D. Duarte, com visibilidade no Leal Conselheiro, coube ao nosso colega João Dionísio retomar as sugestões de Joaquim de Carvalho; também no Brasil o tema tem sido estudado, nomeadamente por Márcio Coelho Muniz. Tendo em conta, porém, que a maior parte destes trabalhos se situam no campo da linguística ou da "cultura", tal como é praticada no contexto dos estudos literários, justifica-se este nosso olhar de historiador, apenas indiciado por Luís Adão da Fonseca.

D. Afonso era o terceiro filho do judeu converso Paulo de Santa Maria ${ }^{9}$ e faz parte de uma linhagem notável pela sua cultura e pelas posições chave na em altos cargos nas cortes ibéricas e na cúria papal.

Bastará situa-lo um pouco antes da sua primeira estada em Portugal $(\text { GALLARDO, 2012) })^{10}$. Vejamos as sucessivas nomeações para cargos eclesiásticos: em Fevereiro de 1415, ainda por Bento XIII, deão de Santiago de Compostela, cargo de grande prestígio e de elevados benefícios económicos; três anos mais tarde para deão de 
Segóvia por Martinho V, com quem privara no concílio de Constança; em Dezembro de 1417, para núncio apostólico e recebedor pontifício, cargo que ocupa até 1427; em Janeiro de 1421 para cónego da catedral de Burgos, para cuja diocese será nomeado bispo em 1435 .

Convém frisar que tais cargos exigiam grande aptidão jurídica, conhecimento das instituições eclesiásticas e capacidade de negociação entre poderes, em época de tão conturbadas relações entre a Igreja e a monarquia após o final do Cisma e a crescente afirmação do poder régio face à Igreja. Mas os estudos de direito civil e canónico (na universidade de Salamanca), assim como o da teologia (com os dominicanos) conferemlhe competências para tal. Homem de confiança de Juan II de Castela, são-lhe confiadas diversas missões diplomáticas, entre elas à corte portuguesa.

Afonso de Cartagena esteve quatro vezes em Portugal acompanhado pelo secretário de Juan II, o doutor Juan Alfonso de Zamora: a primeira, entre Outubro ou Dezembro de 1421 e Dezembro, de 1422; depois em 1423, de Janeiro a Abril; regressa em Dezembro de 1424 e fica até Abril de 1425; finalmente, em 1427, entre Setembro de Dezembro.

Sabemos que a presença de D. Afonso na corte portuguesa foi enriquecedora para ambas as partes, nomeadamente no plano do humanismo (COELHO, 2005, p. 263). Não podemos contudo olvidar o objectivo das suas missões, o qual foi a negociação da paz entre Portugal e Castela. Foram várias etapas negociais até à paz definitiva de 1431, pois estavam em causa, variadas questões territoriais e financeiras, a considerar no complexo conspecto das diversas facções que se erguiam em Castela e Aragão e que não são alheias as morosas negociações com vista ao casamento de D. Duarte com D. Leonor de Aragão. Aliás, sabemos que os negociadores, por parte de Castela, foram precisamente D. Afonso de Cartagena e Juan Alfonso de Zamora (VENTURA, 2011b, p. 9).

D. Alfonso de Cartagena era um homem da esfera do poder, tal como o D. Duarte que irá encontrar, já associado ao trono desde 1413. Ambos mantiveram proveitosas conversas sobre matérias familiares ao infante, segundo o testemunho do próprio D. Afonso (CAMPOS SOUTO, 2004, p. 193) ${ }^{11}$.

Sabemos que é D. Duarte que lhe encomenda o Memoriale Virtutum, mas essa relação intelectual irá dar frutos, não só em formulações de teor ético político, mas também em decisões de governança no plano legislativo. Com efeito, encontramos dispersos pelo Leal Conselheiro - cuja escrita se pode balizar entre 1422 e 1437 - 
muitos temas ou tendências de pensamento que só mais tarde surgirão em obras de Cartagena: sobre o equilíbrio e a natureza das relações entre a Igreja e o Estado, sobre a obediência ao papa, sobre a responsabilidade dos reis na reforma da igreja, sobre o tratamento laical a conferir a judeus e mouros, sobre a predestinação, sobre a unidade dos cristãos (a qual deveria incluir a integração plena dos conversos), assim como questões de utilidade imediata, nomeadamente normas sobre o modo de traduzir textos clássicos... ou mesmo a semelhança no estilo, claro e simples, com a introdução de histórias exemplos quotidianos...

Não é aqui ocasião de seguir a carreira eclesiástica e política de D. Afonso, esta última interferindo, de forma bem negativa nas pretensões de Portugal em relação às Canárias e, de modo ainda mais acintoso, no palco do concílio de Basileia, bloqueando a pretensões da conquista do Benamarim. Há que entender que o cronista e canonista de grande envergadura que foi D. Afonso esteve sempre, e em todas as questões, ao lado dos transtâmaras e da monarquia castelhana. Mas as contradições que D. Duarte recebeu de D. Afonso situam-se dez anos depois da sua última estada em Portugal. Se, como é provável, as teses nas Allegationes (GALLARDO, 2002, p.187s), expostas perante o concílio de Basileia, tinham sido construídas e amadurecidas muito tempo antes, tal não tem eco nos escritos eduardinos. Aliás, D. Duarte refere-se a D. Afonso como "deão de Santiago" (cargo mais marcante para os leitores da corte portuguesa do que o de deão de Segóvia) e não como bispo de Burgos, donde se deduz que essa amizade é anterior a 1435: antes, pois, das penosas intervenções de D. Afonso no concílio. O que permanece é a mútua admiração nascida de profícuos diálogos.

No Capítulo L do Leal Conselheiro D. Duarte propõe-se discorrer sobre as virtudes teologais (Fé, Esperança e Caridade) e "principais"12, (Prudência, Justiça, Temperança e Fortaleza) necessárias a todos os cristãos e mencionadas em obras de judeus, mouros e gentios... Diz que o assunto "é mui cumpridamente" tratado em três obras: o "Regimento dos Príncipes que compôs Frei Gil de Roma", no "Memorial das Virtudes que das Éticas de Aristóteles me ordenou o adião de Santiago" e no "Pomar das Virtudes, que fez mestre André de Paz, ministro dos Frades Menores em Sicília”. D. Duarte socorre-se de duas obras de teologia moral, célebres na época.... Que lhe teriam chegado ..... via aragonesa (rei da Sicília). E, nesse contexto, menciona uma obra 
escrita a seu pedido pelo deão de santiago, identificado há muito como sendo Afonso de Cartagena.

Repare-se que neste capítulo em que nos fala da encomenda do Memorial das Virtudes D. Duarte, além de mencionar as referidas obras de autores cristãos mais ou menos seus contemporâneos, logo convoca os pagãos Valério Máximo e o inevitável Túlio Cícero, do qual refere o De Officiis... e depois volta aos cristãos referindo São João Cassiano e os seus Estabelecimentos; no capítulo seguinte prossegue com várias obras de Aristóteles e chega ao Polycraticus de João de Salisbury passando pelo Epitoma Rei Militaris (a que chama Livro da Cavalaria) de Vegécio. Estas obras - como quer que se chamassem ou quais fossem - funcionam como espelhos para o seu próprio espelho, que é o Leal Conselheiro.

Recentes estudos consideram o Memoriale Virtutum como a "primogénita" (segundo Vina Liste) da vastíssima produção de Afonso de Cartagena. Concluída, com toda a probabilidade, no verão de 1422 foi, como muitas outras, escrita a pedido de um grande senhor: desta vez, como já se disse, a pedido do infante D. Duarte, segundo o testemunho do próprio. O mesmo facto irá ser referido no prólogo do anónimo tradutor do Memoriale Virtutum) ${ }^{13}$.

Mas a intervenção do infante vai para além da encomenda. De facto, D. Afonso começa o tratado por esclarecer as circunstâncias e intenções desse seu escrito, mencionando o conhecimento que D. Duarte possuía das virtudes - não por leituras mas por experiência - e a forma humilde como aprendia mais e ensinava o seu saber e, finalmente, como o mandara passar a escrito o teor desses diálogos (CAMPOS SOUTO, 2004, p. 191-193) ${ }^{14}$.

Portanto, D. Afonso quis recuperar através da escrita o teor de conversas havidas em corte ${ }^{15}$, registando os seus fundamentos teóricos, de tal forma que o saber de D. Duarte, adquirido na vida mais do que em livros, pudesse frutificar nele e nos outros.

Cartagena entrega, pois, a D. Duarte uma obra pedagógica a qual, partindo de pouco formais diálogos de aprendizagem e de ensino, deveria ser útil na formação de um futuro rei. Ambos professavam a convicção na capacidade de mudança do homem, no dever de influir no curso dos acontecimentos ${ }^{16}$; e também no dever de proporcionar aos súbitos menos conhecedores os fundamentos da teologia moral.

Mais: a estas bases da formação cristã, Cartagena juntava as obras da antiguidade que considerava úteis, com relevo para Cícero. D. Afonso, durante a sua 
primeira estada em Portugal, traduz para castelhano o De senectute, o De Officiis, o De inventione ( a Rethórica) e a Oratio pro Marcello ${ }^{17}$.

O Memoriale virtutum foi escrito seguindo de perto os livros III a VII da Ética a Nicómaco. Porém, a exemplo de S. Tomás de Aquino ${ }^{18}$, que segue de perto, D. Afonso compagina o aristotelismo com o cristianismo. Assim, o enlace entre o conhecimento da virtude por parte do rei e a capacidade de bem governar os seus súbditos está bem presente no tão aristotélico Capítulo LI do Leal Conselheiro. Depois de citar Aristóteles - “aqueles são prudentes, que sabem reger si e outros para fim convinhável - D. Duarte explica esta afirmação recorrendo a um exemplo corrente: é a virtude da prudência que garante que os reis verdadeiramente o sejam, e não mera suposição de algo a haver, como os dinheiros dos contadores ${ }^{19}$.

O estudo, prática e exemplo das virtudes em especial da prudência, entram, deste modo, numa corrente activa de ensino e transmissão com vista ao bem comum. Mas, no começo de tudo, está o conhecimento, adquirido em conversas com sabedores ou através da leitura, num louvor à razão e à inteligência ao qual não foi alheio o convívio com Afonso de Cartagena.

Regressemos ao eixo do nosso trabalho: as virtudes conhecidas, praticadas e ensinadas pelo rei como forma de coesão da uma "nova geração de gentes" de que fala Fernão Lopes: nova nobreza, novos criados e apaniguados, todos em redor da nova dinastia e da nova corte. ... Tendo em vista proveitos na ordem interna e externa. Os “espelhos” proporcionavam essa dinâmica, a qual tem, não só intencionalidade interna, mas no plano exterior da cristandade em geral.

No prefácio em forma de dedicatória ${ }^{20}$ que D. Duarte escreve no Leal Conselheiro, dirigido a D. Leonor, ele mesmo sugere o nome que sua esposa poderá dar a essa obra. E justifica a escolha de Leal Conselheiro: escrevera tudo com tanta lealdade quanto lhe permitira o seu pouco saber, colhido na prática da justiça e na escuta de conselhos por todo o seu reino. D. Duarte continua, clarificando o teor e a finalidade da obra como as primeiras letras para a aprendizagem da lealdade, porque aqueles a quem se destina - "senhores e gente de suas casas" - são como crianças em comparação com os sábios. D. Duarte não se exclui dessa menoridade, tanto mais que a sua própria aprendizagem se fez mais na observação do quotidiano do que na obra de letrados. 
Interessante, esta insistência no saber adquirido no contacto experiencial por todo o reino, como que contrastando com as múltiplas referências a obras de grande erudição. Mas afinal é o rei que fala, valorizando a sua relação com os seus súbditos. E é para descrever esta dinâmica que D. Duarte usa o conceito de lealdade.

A lealdade pode manter-se (apesar dos nossos pecados mas com o nosso esforço) em relação “a Nosso Senhor Deus e às pessoas que se deve guardar”. O objectivo da lealdade vai, pois, muito para além da ascética. Ou melhor, D. Duarte forja a sequência entre a lealdade a Deus e a lealdade aos outros: em Portugal essa virtude existe (e será mesmo uma marca identitária dos portugueses, como dirá noutro local ${ }^{21}$ ) entre senhores e servidores e entre maridos e mulheres, assim como entre rei e reino. Mais: a lealdade, que podemos agora traduzir por coerência, existe entre ele próprio e o que escreve.

No Leal Conselheiro é, pois, manifesto o entrosamento com as questões da governança, quer na origem dos escritos e da sua compilação, quer na sua finalidade, assim como no original desenvolvimento do conceito de lealdade. Para correcto entendimento de todos os escritos eduardinos, insistimos, jamais nos poderemos alhear de que o Autor é rei e que mesmo as suas relações com D. Leonor - embora pareça ter existido amor mútuo- são de ordem política (VENTURA, 2011b, p.40 s).

"Da guarda da lealdade em que faz fim todo este tratado": é este o título do último capítulo do Leal Conselheiro, antes anunciado (LRI), o qual encerra com a declaração final baseada numa sistematização dos livros "que tratam de moral filosofia". Nele D. Duarte fecha este conjunto tão variado com a declaração final baseada numa sistematização dos livros "que tratam de moral filosofia". D. Duarte segue a pari passu o início do Memorial, que Cartagena intitulou "Distinción general de toda moral philosophía". Tal como o seu mestre, explica que todos os que tratam desse tema "declaram nosso regimento se partir em tres partes": a da própria pessoa, alma e corpo; a segunda, que pertence à casa, ou seja, mulher, filhos, servidores e todos os outros bens; a terceira, que diz respeito ao reino, cidade ou "qualquer julgado". Mas logo segue o seu caminho, quer prescindindo das referências às obras de Aristóteles, quer introduzindo exemplos retirados da sua vida interior, familiar e de governo. Mais: como vimos, introduz a lealdade como elemento que nos permite cumprir as nossas obrigações nos três planos acima indicados: "todos estes por lealdade recebem grande ajuda para serem bem governados". 
Escalpelizada toda a filosofia moral com recurso a sabedores pagãos e cristãos, provada a necessidade da sua transmissão a todos - sobretudo gente com responsabilidade, quer eclesiásticos, quer leigos - D. Duarte envolve o universo dos súbditos no mesmo plano de exigência com vista, não só à salvação, mas ao bem comum. Ou melhor, numa nova forma de espiritualidade, muito em conexão com as tendências presentes em Portugal propõe modos de realização plena da vivência cristã de acordo com o status.

Não é de somenos que D. Duarte explicite essa relação entre a virtude e a sua realização, concretizada na condição particular de cada um. Porque, obviamente, inclui todos para além dos "oradores", D. Duarte entra nessa corrente a que Vauchez chamou a “idade dos leigos (VAUCHEZ, 1987, p. 10); dirigindo- se D. Duarte aos senhores, gente de suas casas e, no geral, a todos os que têm "vida activa", ensina-lhes os fundamentos de um reino justo, próspero e.... feliz.

Numa crítica alargada aos cinco estados em que divide a sociedade, D. Duarte acusa a tibieza de causar comportamentos contrários ao bem próprio e ao bem comum. No que concerne aos defensores - nos quais se inclui a nobreza - podemos completar o modelo traçado por D. Duarte com outras considerações incluídas mais adiante no Leal Conselheiro: que sigam as recomendações de São João Baptista, não oprimindo ou injuriando os mais fracos, que estejam sempre prontos para defender o seu senhor e despendam os seus bens em seu favor, que não abandonem o serviço da coisa pública antes dos quarenta anos, e, se possível, sirvam até à idade de setenta anos, que tenham saúde e porfiem em alcançar glória, que cuidem da sua fazenda, que conservem e aumentem a sua honra e bens, que mantenham também em boa honra os que dele dependem, que vivam com alegria (cap. LXXXV). D. Duarte afirma que tal foi cumprido exemplarmente pelo Condestável e que isso deverá contar no seu processo de canonização, iniciado, como se sabe, por volta de 1433.

Disponiblidade e esforço com vista ao bem comum são exigidos noutros termos aos lavradores, pescadores, oficiais de variadas "artes aprovadas" e mesteres: empenho em, pelo seu trabalho, retirar da terra e do mar os frutos com que nos sustentemos, conhecimento dos respectivos ofícios, solicitude, trabalho com lealdade e no temor de Deus. Todos, enfim, devem suportar as tarefas e os perigos inerentes ao seu status e não usufruir dele somente o que é folgado e seguro. 
Está completo o círculo, que porventura Afonso de Cartagena induziu junto do jovem D. Duarte: cultura, virtude, prossecução do bem comum e eficácia na governança do reino.

\section{MIRROR OF MIRRORS. D. DUARTE IN THE COMPANY OF D. AFONSO OF CARTAGENA BETWEEN CULTURE, MORALITY AND POLITICS.}

ABSTRACT: The presence of D. Alfonso de Cartagena in the Portuguese court of Avis adds to the long tradition of the "mirrors of Kings" a new look: based on both classic authors like in Sacred Scripture and the Doctors of the Church, induces the young Prince heir to the study, imitation and transmission of ascetic and behavioral models. D. Duarte takes these requirements, not only for himself but for his court, as a matrix for all his subjects. In teaching fitness for each status, the virtues required by princes are redistributed so that everyone can look himself on those mirrors.

Keywords: D. Afonso de Cartagena, Avis Court, Mirrors of kings

ESPEJOS DE ESPEJOS... D. DUARTE EM COMPAÑÍA DE D. ALFONSO DE CARTAGENA ENTRE LA CULTURA, LA MORAL Y LA POLÍTICA

RESUMEN: La presencia de D. Alfonso de Cartagena en la corte de Avis se suma a la larga tradición de los "espejos de reyes", una nueva mirada: basada tanto en los autores clásicos como en la Sagrada Escritura y en los doctores de la Iglesia, lleva al joven heredero al estudio, a la imitación y a la transmisión de modelos ascéticos y comportamentales. D. Duarte asume esas exigencias no sólo para sí, sino para su corte, como una matriz para todos sus súbditos. En una didáctica de la adecuación a cada status, las virtudes requeridas a los príncipes se redistribuyen, como para que todos puedan mirarse en esos espejos.

Palabras clave: D. Alfonso de Cartagena, corte de Avis, espejos de reyes.

\section{NOTAS}

${ }^{1}$ Alegoria inserida no Cap. LXXXI do Leal Conselheiro ("Das casas do nosso coração, e como the devem ser apropriadas certas fins"): “[...] Segunda, câmara de paramento, ou antecâmara, em que costumam estar seus moradores e alguns outros notáveis do Reino".

2 Noção de enormes consequências jurisdicionais, presente, p. ex. na famosa carta de Bruges do inf. D. Pedro, e que ganha foros de escândalo na resolução tomada por D. Afonso $\mathrm{V}$ de mandar prender todos quantos não se tenham confessado na quaresma. Ventura (2004), pp. 79-96. 
3 Sobre a especial responsabilidade do rei sobre os moradores da sua casa $v d$. Minuta de carta do Arcebispo de Braga, D. Fernando da Guerra, a D. Afonso V, Braga, 26 e 27 de Fevereiro de 1462, Arq. Distrital de Braga, Gaveta das cartas, doc. 3, publ.: “[...]E parece-me que este vosso boo preposito devees mandar comprir aos da vosa casa que no teem outro curado senom vos, das almas e dos corpos, e delles avees dar conta a Deus e do que elles fezerem. E assy cada huum dos seus que andam vagabundos".

4 Não é fácil definir o que se entende por corte. Prescindindo da análise semântica do termo (de cúria a corte) e de considerações que importam sobretudo à Alta Idade Média, refiram-se os recentes trabalhos de José Martínez Millán.

${ }^{5}$ Cap. XXXIX ("Em que se mostram as partes por que se da e muda nossa condição").

6 Tendência que se alarga ao ensino das damas, como se verificará pela obra de Christine de Pizan.

7 Idem.

8 Para ultrapassar as dúvidas entre a utilização de "Alonso" ou de "Alfonso" traduziremos o nome, tal como o fez Piel (1942) na sua incontornável edição do Leal Conselheiro.

9 Aliás Selomo-há-Levi (1352-1435), rabino-mor da judiaria de Burgos.

$10 v d$. também as notas introdutórias das edições do Doctrinal de los cavalleros (Cartagena) e do Memorial de Virtudes, supra citado.

11 Testemunho inserido na Rhetórica, tradução do De inventione de Cícero realizada numa das suas últimas visitas a Portugal: "Fablando com vos, prínçipe esclaresçido, en materias de sçiençia en que vos bien sabedes fablar, en algunos días de aquel tiempo en que la vuestra corte por mandado del muy cathólico Rey, mi señor, estava" ${ }^{12}$ Actualmente designadas por "cardiais", pois todas as outras se agrupam em torno de elas (Catecismo..., § 1803s).

${ }^{13}$ A tradução, de 1474, foi dedicada a D. Isabel, filha do inf. D. João (sobrinha de D. Duarte), que casara em 1447 com Juan II de Castela. Diz o prólogo: “[...] determiné trasladar en nuestra común lengua castellana un graçioso e noble tratado que de virtudes fallé, el qual de los dichos de los morales filósofos conpuso el de loable memoria don Alfonso de Santa María, obispo de Burgos, al muy ilustre e muy ínclito señor don Duarte, Rey de Portugal, seyendo primero prínçipe, al qual Memorial de virtudes intitulo". Campos Souto (2004), p. 191.

14 “ [...] determiné trasladar en nuestra común lengua castellana un gracioso e noble tratado que de virtudes fallé, el qual de los dichos de los morales filósophos conpuso el Margarida Garcez Ventura. Espelhos de espelhos... D. Duarte na companhia de D. Afonso de Cartagena 
de loable memoria don Alfonso de Santa Maria, obispo de Burgos, al muy ilustre e muy ínclito señor don Duarte, Rey de Portugal, seyendo primero prinçipe, al qual Memorial de virtudes intitulo." Campos Souto (2004), p. 193.

${ }^{15} \grave{A}$ semelhança das conversas sobre as relações familiares mantida com os cunhados, os infantes de Aragão: conversa convertida em carta (guardada nos seus papéis (Livro dos Conselhos..., [61.]) e incluída no cap. 98 do L. C.

16 "Optimismo ontológico" (Cândida Pacheco) fundado no auxílio da Graça, na exaltação do livre-arbítrio e a absoluta recusa da predestinação; Campos Souto (2004), p. 27, n. 37.

${ }^{17}$ Ibidem, pp. 36-37.

${ }^{18}$ Ibidem, pp. 29-31.

19 Como se sabe os contadores eram oficiais reais ou senhoriais que procediam à arrecadação de dinheiro e outros bens.

${ }^{20}$ Alguns dos temas presentes neste prefácio marcarão presença na posterior obra de Cartagena Doctrinal de los Cavalleros. Por exemplo, nela se alude também ao debate ciceroniano, tão querido no século XVI (lembremos Camões) entre o estudo e as obrigações da "espada", ou, de modo mais alargado, as da governança. (Cartagena, 1995), Introdução, p. XXXII n. 72.

${ }^{21}$ No já citado Cap. XXXIX ("Em que se mostram as partes por que se da e muda nossa condição"), ao mencionar como são em geral os portugueses diz que "são leais e de bons corações".

\section{REFERÊNCIAS}

ALBUQUERQUE, Martim de, O Poder Político no Renascimento Português. $2^{\mathrm{a}}$ ed. Revista. Lisboa: Verbo / Babel, 2012.

CAMPOS SOUTO, Mar, El Memorial de virtudes: la traducción castellana del Memoriale Virtutum de Alfonso de Cartagena. Burgos: Instituto Municipal de Cultura, Ayuntamiento de Burgos, 2004.

CARTAGENA, Alonso de. Defensorium Unitatis Christianae: un tratado en favor de los conversos, por Santiago Garcia-Jalón de la Lama, Salamanca, Universidade Pontifícia, 1990.

CARTAGENA, Alonso de. Doctrinal de los cavalleros, Edição de José Maria VIÑA LISTE. Santiago de Compostela: Universidade de Santiago de Compostela, 1995. 
Catecismo da Igreja Católica. Coimbra: Gráfica de Coimbra, 1993.

COELHO, Maria Helena da Cruz, D. João I, Lisboa, Círculo de Leitores, 2005.

CRISPIM, Maria de Lourdes Crispim. O Livro das Tres Virtudes ou o Espelho de Cristina. Dissertação de Doutoramento em Linguística. Lisboa: Universidade Nova de Lisboa, 1995.

DUARTE, D. Livro dos Conselhos de El-Rei Dom Duarte. Livro da Cartuxa. Transcrição de João José Alves Dias, Intr. E revisão de A. H. de Oliveira Marques. Lisboa: Estampa, 1982.

DUARTE, D. Leal Conselheiro. Actualização ortográfica, introdução e notas de João Morais Barbosa. Lisboa: Imprensa Nacional-Casa da Moeda, 1982.

DUARTE, D. Leal conselheiro o qual fez Dom Eduarte Rey de Portugal e do Algarve e Senhor de Cepta. Ed. Joseph M. Piel. Lisboa: Bertrand, 1942.

DUARTE, Luís Miguel. D. Duarte, Lisboa: Círculo de Leitores, 2005.

FERNÁNDEZ GALLARDO, Luís. Alonso de Cartagena: uma biografia política en la Castilla del siglo XV. Valladolid: Junta de Castilla y León, 2002.

VAUCHEZ, André. Les laics au Moyen Âge. Pratiques et expérienses religieuses. Paris: Ed. du Cerf, 1987.

VENTURA, Margarida Garcez. Cristãos da primitiva Igreja: uma aproximação à reforma da Igreja no Portugal quatrocentista, Actas do VI Encontro Luso-Brasileiro de História Medieval. Coimbra, 2013 a.

VENTURA, Margarida Garcez. D. Duarte: vivência religiosa e ofício de reinar". D.

Duarte e a sua época: arte, cultura, poder e espiritualidade, Lisboa, Instituto de Estudos Medievais, Universidade Nova de Lisboa, 2013 b.

VENTURA, Margarida Garcez, Uma lâmpada de prata e muito mais: testemunhos de D. Duarte sobre a santidade de Nuno Álvares Pereira. Revista Portuguesa de História do Livro, Ano XIV, Vol. 27 , 2011 a.

VENTURA, Margarida Garcez e ARAÚJO, Julieta, D. Leonor de Aragão. A Triste Rainha. 1402 (?) - 1445. Matosinhos: QuidNovi / Academia Portuguesa da História, 2011 b.

VENTURA, Margarida Garcez. O ofício de rei no Portugal quatrocentista. Teoria e práticas de poder. O Portugal Medieval. Monarquia e Sociedade. Org. Carlos Nogueira. São Paulo: Alameda, 2010. p.125-141 
VENTURA, Margarida Garcez, Poder régio e poder eclesiástico: cooperação e confronto. Actas da VI Semana de Estudos Medievais. I Encontro Luso-Brasileiro de História Medieval. Brasília: Universidade de Brasília, 2007. 